\title{
PENGARUH TEKNIK RELAKSASI NAFAS DALAM TERHADAP INTENSITAS NYERI IBU BERSALIN KALA I FASE LATEN DI PRAKTIK BIDAN MANDIRI ANATAPURA
}

\section{The Effect of Deep Breathing Relaxation Techniques on The Intensity of Maternal Pain During First Laten Phase in Anatapura Midwifery Clinic}

\author{
Taqwin \\ Poltekkes Kemenkes Palu \\ (taqwin.sahe78@gmail.com, 081358617089)
}

\begin{abstract}
ABSTRAK
Tujuan penelitian ini adalah untuk mengetahui pengaruh teknik relaksasi nafas dalam terhadap intensitas nyeri ibu bersalin kala I fase laten di Praktik Bidan Mandiri Anatapura. Metode preeksperimental pretest-posttest design. Populasi dalam penelitian ini adalah ibu bersalin kala I fase laten di Praktik Bidan Mandiri Anatapura. Teknik pengambilan sampel purposive sampling. Besar sampel sebanyak 15 responden. Analisis yang digunakan adalah analisis univariat dan bivariat menggunakan uji wilcoxon. Hasil penelitian menunjukkan dari 15 responden, sebelum dilakukan teknik relaksasi nafas dalam terdapat 11 orang $(73,3 \%)$ yang mempunyai nyeri sedang dan 4 orang $(26,7 \%)$ yang mempunyai nyeri berat dan sesudah dilakukan teknik relaksasi nafas dalam terdapat nyeri ringan 12 orang $(80 \%)$ dan nyeri sedang 3 orang (20\%). Hasil uji wilcoxon nilai p 0,000 $(\mathrm{P}<0,05)$. Kesimpulan penelitian ada pengaruh teknik relaksasi nafas dalam terhadap intensitas nyeri ibu bersalin kala I fase laten di Praktik Bidan Mandiri Anatapura. Diharapkan bagi bidan di PBM Anatapura berperan aktif dalam memberikan penggunaan metode relaksasi nafas dalam saat persalinan guna menurunkan tingkat nyeri persalinan sehingga dapat meningkatkan pelayanan terhadap pasien.
\end{abstract}

Kata kunci : Teknik relaksasi nyeri, intensitas, ibu bersalin

\section{ABSTRACT}

The object of this research is to determine the effect of deep breathing relaxation techniques on the intensity of maternal pain during the first latent phase in Anatapura Midwifery Clinic. The research method used pre-experimental pretest-posttest design. The research sample was a part of maternity mothers who were selected based on the criteria determined by researchers at Anatapura Midwifery Clinic. The number of samples were 15 respondents. The sampling technique used purposive sampling technique. Data were analyzed by univariate and bivariate analysis with the Wilcoxon test. The results showed that, from total 15 respondents, before the deep breath relaxation technique, there were 11 people (73.3\%) who had average pain and 4 people (26.7\%) who had high pain and after deep breathing relaxation techniques, there were 12 people (80\%) who had low pain and 3 people (20\%) who had average pain. The Wilcoxon test results showed p value 0,000 ( $P<0.05)$. As conclusion, there is an effect of deep breathing relaxation techniques towards the intensity of maternal pain during the first latent phase in the Anatapura Midwifery Clinic. It is suggested for midwives at PBM Anatapura to actively use the deep breathing relaxation methods to reduce labor pain and to improve patient care.

Keywords : Pain relaxation techniques, intensity, maternity 


\section{PENDAHULUAN}

Persalinan adalah proses pengeluaran hasil konsepsi janin atau uri yang telah cukup bulan atau hidup diluar kandungan melalui jalan lahir atau melalui jalan lain, dengan bantuan atau tanpa bantuan. Proses persalinan identik dengan rasa nyeri yang akan dijalani, secara fisiologis nyeri terjadi ketika otot-otot rahim berkontraksi sebagai upaya membuka servik dan mendorong kepala bayi ke arah panggul $^{(1)}$. Selama kala I persalinan normal, nyeri bisa diakibatkan oleh kontraksi involunter otot uteri. Kontraksi cenderung dirasakan dipunggung bawah pada awal persalinan. Sensasi nyeri melingkari batang tubuh bawah yang mencakup abdomen dan punggung ketika persalinan mengalami kemajuan, intensitas setiap kontraksi meningkat, menghasilkan intensitas nyeri yang lebih besar ${ }^{(2)}$.

Berdasarkan penelitian di Amerika Serikat $80 \%$ wanita yang melahirkan mengharapkan persalinan berlangsung tanpa rasa nyeri. Berbagai cara dilakukan agar ibu melahirkan tidak selalu merasa sakit dan merasa nyaman. Di Brazil angka ini mencapai lebih dari 50\% dari angka kelahiran di suatu rumah sakit yang merupakan presentase tertinggi diseluruh dunia. Saat ini hingga 50\% persalinan di rumah sakit swasta di Indonesia dilakukan dengan operasi caesar, tingginya operasi caesar disebabkan para ibu yang hendak bersalin lebih memilih operasi yang relatif tidak nyeri ${ }^{(3)}$. Penanganan dan pengawasan nyeri persalinan terutama pada kala I sangat penting, karena itu sebagai titik penentu apakah seorang ibu bersalin dapat menjalani persalinan normal atau diakhiri dengan suatu tindakan dikarenakan adanya penyulit yang diakibatkan nyeri yang sangat hebat. Intervensi untuk mengurangi ketidaknyamanan atau nyeri selama persalinan yaitu intervensi farmakologis dan non farmakologis. Nyeri persalinan dapat dikurangi/diredakan dengan berbagai metode yaitu menambah pengetahuan ibu tentang halhal yang akan terjadi pada suatu persalinan, menambah kepercayaan diri dan relaksasi pernapasan. Teknik relaksasi bernafas merupakan teknik pereda nyeri yang banyak memberikan masukan terbesar karena teknik relaksasi dalam persalinan dapat mencegah kesalahan yang berlebihan pada proses persalinan. Pernapasan dan relaksasi dinilai sebagai teknik yang "sangat membantu" untuk "mengendalikan nyeri secara komplet" pada multipara $58 \%$ dan $48 \%$ ibu primipara ${ }^{(2)}$.

Beberapa penelitian yang dilakukan sebelumnya $^{(3)}$ bahwa teknik relaksasi nafas dalam berpengaruh terhadap penurunan tingkat nyeri persalinan kala I, hal ini dapat dibuktikan dengan hasil yang telah diperoleh selama penelitian yaitu sebelum diberikan perlakuan teknik relaksasi yaitu nyeri sedang 8 responden (26,67\%), nyeri berat sebanyak 22 responden $(73,33 \%)$, dan setelah diberi perlakuan teknik relaksasi yaitu nyeri ringan sebanyak 11 responden $(36,67 \%)$, nyeri sedang sebanyak 18 responden (60\%), nyeri berat sebanyak 1 responden $(3,33 \%)$. Penelitian menunjukkan 
adanya perbedaan sebelum diberikan teknik relaksasi nafas dalam yaitu 11 orang $(36,7 \%)$ mengalami nyeri sedang dan 19 orang $(63,3 \%)$ mengalami nyeri berat dan setelah diberikan teknik relaksasi nafas dalam mengalami perubahan yaitu 11 orang $(36,7 \%)$ mengalami nyeri ringan, 15 orang $(50,00 \%)$ mengalami nyeri sedang dan 4 orang $(13,3 \%)$ mengalami nyeri berat ${ }^{(4)}$.

Penelitian yang dilakukan oleh Nurfitri (2016) bahwa ada perbedaan intensitas nyeri pada ibu inpartu kala I fase aktif sebelum dan sesudah melakukan teknik relaksasi pernafasan dengan hasil penelitian yang didapatkan, sebelum melakukan teknik relaksasi sebagian besar responden mengalami nyeri sedang yaitu 8 responden dengan presentase $47,1 \%$, nyeri berat yaitu 8 responden dengan presentase $47,1 \%$ dan nyeri sangat berat yaitu 1 responden dengan presentase $5,8 \%$ dan sesudah melakukan teknik relaksasi pernafasan responden mengalami skala nyeri ringan yaitu 6 responden dengan presentase 35,3\%, skala nyeri sedang yaitu 8 responden dengan presentase $47,1 \%$, skala nyeri berat 2 responden dengan presentase $11,8 \%$ dan nyeri sangat berat yaitu 1 responden dengan presentase $5,9 \%{ }^{(5)}$.

Teknik relaksasi nafas dalam merupakan salah satu cara untuk mengurangi rasa nyeri pada ibu bersalin secara non farmakologis dengan menarik nafas dalam-dalam pada saat ada kontraksi melalui hidung sambil menggembungkan perut dan menghembuskan nafas melalui mulut secara perlahan sambil mengempeskan perut ${ }^{(6)}$. Teknik relaksasi dapat dilakukan untuk mengendalikan rasa nyeri ibu dengan meminimalan aktifitas saraf simpatik dalam sistem saraf otonom. Teknik tersebut dapat mengurangi sensasi nyeri dan mengontrol intensitas reaksi ibu terhadap rasa nyeri. Hormon adrenalin dan kortisol yang menyebabkan ibu cemas dan takut akan menurun, ibu dapat meningkatkan konsentrasi dan merasa tenang sehingga memudahkan ibu untuk mengatur pernafasan ${ }^{(7)}$.

Berdasarkan pengambilan data awal pada bulan November-Desember tahun 2017 jumlah ibu yang akan bersalin adalah 36 orang (Klinik PBM Anatapura, 2017). Semakin meningkat jumlah persalinan maka tanggung jawab seorang bidan di tempat-tempat pelayanan kesehatan semakin berat, tugas seorang bidan adalah memberikan asuhan fisik maupun psikologis yang berorientasi pada tubuh selama proses persalinan salah satunya adalah memenuhi kebutuhan dasar ibu dalam masa persalinan kala I khususnya pendekatan untuk pengurangan rasa sakit yaitu dengan mengajarkan ibu teknik relaksasi dan membantu ibu dalam melatih pernapasan ${ }^{(8)}$. Peneliti memilih lokasi penelitian di PBM Anatapura karena saat ini di klinik tersebut, masih kurangnya informasi yang diberikan kepada pasien tentang cara mengatasi nyeri persalinan dengan teknik non farmakologi yaitu teknik relaksasi nafas dalam sehingga ibu tidak dapat mengendalikan rasa nyeri.

Berdasarkan latar belakang di atas peneliti tertarik untuk melakukan penelitian 
tentang "Pengaruh teknik relaksasi nafas dalam terhadap intensitas nyeri ibu bersalin kala I fase laten di praktik Bidan Mandiri Anatapura.

\section{METODE PENELITIAN}

Dilaksanakan pada tanggal 09 Juni-19 Juli 2018 di Praktik Bidan Mandiri Anatapura. Rancangan pretest-posttest design. Populasi adalah ibu bersalin kala I fase laten di Praktik Bidan Mandiri Anatapura. Teknik purposive sampling dimana pengambilan sampel diambil berdasarkan karakteristik yang ditentukan oleh peneliti sendiri. Kriteria sampel yang digunakan yaitu: Kriteria inklusi Ibu yang tidak menggunakan metode farmakologi untuk mengurangi nyeri. Status persalinan multigravida. Sampel sebanyak 15 orang. Peneliti mengajarkan dan meminta responden untuk menilai nyeri yang dirasakan ketika kontraksi uterus His pertama menggunakan lembar observasi Numeric Rating Scale dengan penentuan tingkat nyeri berdasarkan nyeri ringan, nyeri sedang, nyeri berat, nyeri yang paling hebat. Peneliti mengajarkan kepada responden tentang cara mengatur pola pernapasan dengan teknik relaksasi nafas dalam dengan cara menarik nafas lewat hidung sambil menggembungkan perut dan menghembuskan nafas secara perlahan melalui mulut. Memasuki fase aktif, responden menerapkan teknik relaksasi nafas dalam yang diajarkan oleh peneliti. Responden menilai kembali nyeri yang dirasakan ketika His kedua dan His ketiga dengan menunjukkan skala nyeri pada lembar Numeric Rating Scale. Analisis dengan uji wilcoxon Signed Rank Test.

\section{HASIL}

Praktik Bidan Mandiri (PBM) Anatapura adalah institusi pelayanan kesehatan yang berada di Jl. Tembang Kelurahan Kamonji Kecamatan Palu Barat Kota Palu. Bidan Praktik Mandiri Anatapura terdiri atas 5 ruangan yaitu ruangan adminitrasi, ruang Antenatal Care, ruang Intranatal Care, ruang Postnatal Care dan Musholla. Bidan yang bertugas diklinik tersebut berjumlah empat orang, masing-masing memiliki waktu bertugas yang terbagi atas pagi, sore, dan malam. Cakupan persalinan di PBM cukup tinggi, dalam waktu 1 bulan bisa mencapai 2028 ibu bersalin. Penatalaksanaan asuhan kebidanan intranatal di klinik tersebut sudah menggunakan prosedur Asuhan Persalinan Normal 60 langkah tetapi belum menerapkan penatalaksanaan nyeri non farmakologi yaitu teknik relaksasi nafas dalam.

Tabel 1. Karakteristik tingkat nyeri persalinan kala I fase laten sebelum dilakukan teknik relaksasi nafas dalam di Praktik Bidan Mandiri Anatapura tahun 2018

\begin{tabular}{lcc}
\hline Tingkat nyeri & $\mathbf{n}$ & $\mathbf{\%}$ \\
\hline Nyeri ringan & 0 & 0 \\
Nyeri sedang & 11 & 73,3 \\
Nyeri berat & 4 & 26,7 \\
Nyeri yg paling hebat & 0 & 0 \\
Total & 15 & 100 \\
\hline
\end{tabular}

Sumber : Data primer, 2018

Berdasarkan tabel 1 menunjukan tingkat nyeri sebelum dilakukan teknik relaksasi nafas dalam yaitu nyeri sedang berjumlah $11 \mathrm{ibu}$ bersalin $(73,3 \%)$, nyeri berat berjumlah $4 \mathrm{ibu}$ bersalin $(26,7 \%)$. 
Tabel 2 Karakteristik tingkat nyeri persalinan kala I fase laten sesudah dilakukan teknik relaksasi nafas dalam di Praktik Bidan Mandiri Anatapura tahun 2018

\begin{tabular}{lcc}
\hline \multicolumn{1}{c}{ Tingkat nyeri } & n & \% \\
\hline Nyeri ringan & 12 & 80 \\
Nyeri sedang & 3 & 20 \\
Nyeri berat & 0 & 0 \\
Nyeri yang paling hebat & 0 & 0 \\
\hline Total & 15 & 100
\end{tabular}

Sumber : Data primer, 2018

Berdasarkan tabel 2 menunjukkan tingkat nyeri sesudah dilakukan teknik relaksasi nafas dalam yaitu nyeri ringan berjumlah $12 \mathrm{ibu}$ bersalin (80\%), nyeri sedang berjumlah $3 \mathrm{ibu}$ bersalin (20\%).

Tabel 3 Pengaruh Teknik Relaksasi Nafas dalam Terhadap Intensitas Nyeri Ibu Bersalin Kala I Fase Laten di Praktik Bidan Mandiri Anatapura

\begin{tabular}{llcc}
\hline & & n & p-value \\
\hline Sesudah & Negative Ranks & $15 \mathrm{a}$ & \\
teknik & & & \\
Relaksasi & Positive Ranks & $0 \mathrm{~b}$ & 0,000 \\
sebelum & Ties & $0 \mathrm{c}$ & \\
Teknik & Total & 15 & \\
relaksasi & & & \\
\hline
\end{tabular}

Berdasarkan tabel 3 dapat diketahui responden yang mengalami penurunan nyeri yaitu 15 responden. Hasil uji Wilcoxon nilai $\mathrm{p}=$ value 0,000 jika dibandingkan dengan $\alpha=0,05$, maka nilai tersebut menunjukkan $P$ value $<\alpha$, sehingga dapat disimpulkan bahwa Ha diterima dan HO ditolak. Hal tersebut menunjukkan bahwa terdapat pengaruh teknik relaksasi nafas dalam terhadap intensitas nyeri pada ibu bersalin kala I fase laten yang terlihat dari hasil post test tingkat nyeri persalinan mengalami penurunan.

\section{PEMBAHASAN}

Penelitian ini dilaksanakan mulai tanggal 09 Juni sampai 19 Juli 2018. besar sampel sebanyak 15 responden yang memenuhi kriteria untuk menjadi subjek penelitian. Peneliti menjelaskan teknik relaksasi nafas dalam dan responden memberi penilaian nyeri pretest pada kontraksi uterus his pertama fase laten. Memasuki fase aktif, responden menerapkan teknik relaksasi nafas dalam dengan menarik nafas melalui hidung sambil menggembungkan perut dan menghembuskan nafas secara perlahan melalui mulut sambil mengempeskan perut. Kemudian responden memberi penilaian nyeri posttest pada his kedua dan his ketiga.

Berdasarkan tabel 3 menunjukkan adanya penurunan nyeri setelah dilakukan teknik relaksasi nafas dalam pada responden. Berdasarkan hasil observasi sebelum diberikan teknik relaksasi nafas dalam terdapat $11 \mathrm{ibu}$ bersalin $(73,3 \%)$ yang mempunyai nyeri sedang dan 4 ibu bersalin $(26,7 \%)$ yang mempunyai nyeri berat dan sesudah dilakukan teknik relaksasi nafas dalam terdapat $12 \mathrm{ibu}$ bersalin (80\%) yang mempunyai ringan dan 3 ibu bersalin (20\%) yang mengalami nyeri sedang.

Asumsi peneliti bahwa hal ini berpengaruh terhadap persepsi nyeri dan kemampuan kontrol diri pada ibu tentang proses persalinan, ibu yang belum bisa mengendalikan nyeri yang dirasakan dalam proses persalinan akan sulit mengontrol nyeri yang dirasakan terkait dengan belum adanya 
penanganan nyeri yang didapatkan yaitu teknik relaksasi nafas dalam. Pembukaan serviks juga mempengaruhi intensitas nyeri yang dirasakan, semakin bertambahnya intensitas nyeri yang diikuti oleh proses pembukaan serviks maka nyeri yang dirasakan akan bertambah besar. Kecemasan yang dirasakan ibu bermula pada kala I fase laten sampai memasuki fase aktif. Hal tersebut dapat dilihat dari mimik wajah saat peneliti melakukan observasi, responden nampak mendesis sehingga mempengaruhi intensitas rasa nyeri pada persalinan.

Nyeri persalinan sebagai kontraksi miometrium, merupakan proses fisiologis dengan intensitas yang berbeda pada masingmasing individu. Nyeri bertambah ketika mulut rahim dalam ber dilatasi penuh akibat tekanan bayi terhadap struktur panggul diikuti regangan dan perobekan jalan lahir. Nyeri persalinan dianggap suatu yang biasa/wajar, namun mereka belum memiliki pengalaman tentang cara yang dapat dilakukan untuk mengurangi nyeri seperti teknik relaksasi nafas dalam. sehingga peneliti tertarik untuk mengajarkan teknik relaksasi nafas dalam untuk mengurangi nyeri persalinan ${ }^{(9)}$.

Kemampuan responden dalam menerapkan teknik relaksasi nafas dalam dan bidan memberikan sugesti yang positif untuk mengalihkan perhatian responden, sehingga membuat responden terbantu dalam mengatasi kecemasan dan terjadi penurunan intensitas nyeri sehingga responden menjadi lebih rileks dalam menghadapi persalinan. Hal ini diperkuat oleh teori maryunani (2010) Teknik relaksasi nafas dalam ini merupakan salah satu metode penghilang rasa nyeri secara non farmakologi. Pada prinsipnya, teknik relaksasi nafas dalam ini dapat mengurangi ketegangan pada ibu yang membuat stress pada saat nyeri persalinan, dengan dilakukanya teknik relaksasi nafas dalam ini dapat mengendalikan nyeri dengan meminimalkan aktifitas saraf simpatik dalam sistem saraf otonom. Teknik tersebut dapat mengurangi sensasi nyeri dan mengontrol intensitas reaksi ibu terhadap rasa nyeri. Hormon adrenalin dan kortisol yang menyebabkan stres akan menurun, ibu dapat meningkatkan konsentrasi dan merasa tenang sehingga memudahkan ibu untuk mengatur pernafasan.

Berdasarkan hasil uji Wilcoxon diperoleh nilai $\mathrm{p}$ value sebesar $=0,000$ jika dibandingkan dengan $\alpha=0,05$, maka nilai tersebut menunjukkan $\mathrm{p}$ value $<\alpha$, sehingga dapat disimpulkan bahwa $\mathrm{Ha}$ diterima dan $\mathrm{HO}$ ditolak. Hal tersebut menunjukkan bahwa terdapat pengaruh teknik relaksasi nafas dalam terhadap intensitas nyeri pada ibu bersalin kala I fase laten di Praktik Bidan Mandiri Anatapura. Hasil penelitian ini juga didukung oleh penelitian Ghofur tahun $2010^{(10)}$ pada ibu bersalin kala I dengan hasil bahwa teknik relaksasi nafas dalam efektif untuk mengurangi nyeri selama proses persalinan berlangsung. Demikian pula, penelitian yang dilakukan oleh Fatmawati tahun 2011(11) pada pasien persalinan normal kala I fase laten dengan hasil bahwa intensitas nyeri sebelum diberikan teknik relaksasi pernafasan rata-rata 
mengalami nyeri berat dan sesudah diberikan

teknik relaksasi pernafasan rata-rata mengalami nyeri ringan.

Sesuai dengan hasil penelitian bahwa teknik relaksasi nafas dalam terhadap nyeri persalinan kala I fase aktif pada ibu bersalin di PBM Anatapura dapat menurunkan nyeri persalinan pada ibu bersalin, hal ini dibuktikan berdasarkan adanya penurunan hasil posttest. Oleh karena itu, teknik relaksasi nafas dalam dapat digunakan sebagai intervensi dalam asuhan kebidanan ibu bersalin kala I untuk mengurangi persalinan.

\section{KESIMPULAN DAN SARAN}

Berdasarkan pembahasan diatas dapat disimpulkan bahwa ada pengaruh intensitas nyeri sebelum dan sesudah diberikan teknik relaksasi nafas dalam terhadap intensitas nyeri persalinan kala I fase laten. Diharapkan bidan di PBM Anatapura berperan aktif dalam memberikan penggunaan metode relaksasi nafas dalam saat persalinan guna menurunkan tingkat nyeri persalinan sehingga dapat meningkatkan pelayanan terhadap pasien. Bagi institusi pendidikan, penelitian diharapkan dapat digunakan untuk pengembangan ilmu pengetahuan kebidanan terutama dalam penanganan nyeri persalinan. Bagi ibu bersalin, diharapkan ibu bersalin kala I fase laten dapat menjadikan teknik relaksasi nafas dalam sebagai upaya untuk menurunkan nyeri persalinan yang dirasakan karena teknik relaksasi nafas dalam terbukti memiliki pengaruh dalam menurunkan nyeri persalinan.

\section{DAFTAR PUSTAKA}

1. Naomy, Marie T. Asuhan Kebidanan Persalinan dan Bayi Baru Lahir. Jakarta: In Media; 2016

2. Reeder SJ, Leonide \& Deborah, K.G Keperawatan Maternias Kesehatan Wanita, Bayi, \& Keluarga. Jakarta; EGC; 2014.

3. Wildan, M. Pengaruh Teknik Relaksasi Terhadap Adaptasi Nyeri Ibu Bersalin Kala I Fase Aktif di BPS Wilayah Puskesmas Patrang Kabupaten Jember Tahun 2012, (Online). Diakses 24 Oktober 2017.

4. Winny, P. Naskah Publikasi. Pengaruh Teknik Relaksasi Nafas Dalam Terhadap Respon Adaptasi Nyeri pada Ibu Inpartu Kala I Fase Aktif di BPM Bidan P di Kota Yogyakarta; 2014 (Online). Diakses 24 Oktober 2017

5. Nurfitri, Perbedaan Intensitas Nyeri pada Ibu Inpartu Kala I Fase Aktif Sebelum dan Sesudah Melakukan Teknik Relaksasi dengan Pernapasan di RB "R", (Online) 2016

6. Yesie, A. Bebas Takut Hamil dan Melahirkan. Jakarta: Gramedia Pustaka Utama; 2017.

7. Maryunani, A. Nyeri dalam Persalinan "Teknik dan Cara Penangananya". Trans Info Media: Jakarta; 2010

8. Dainty, M. Asuhan Kebidanan Persalinan. Binarupa Aksara, Tangerang; 2016.

9. Sulistyo, A \& Suharti. Persalinan Tanpa Nyeri Berlebihan. Yogyakarta: Ar-Ruz Media; 2013.

10. Ghofur, Abdul. Pengaruh Teknik Relaksasi Nafas Dalam Pada Pasien Inpartu kala I Fase Laten di Rumah Bersalin Depok Jaya. Jakarta: Universitas Pembangunan Nasional Veteran; 2010 (Online). Diakses 24 Oktober 2017

11. Fatmawati, Lis. Pengaruh Teknik Relaksasi Pernafasan Terhadap Tingkat Rasa Nyeri Pada Ibu Bersalin Kala I di BPS Mu'rofah. Surabaya: Universitas Muhamadiyah Surabaya; 2011 (Online) Diakses 24 Oktober 2017. 